\title{
Vascular supply as a discriminating factor for pig preantral follicle selection
}

\author{
A Martelli, N Bernabò, P Berardinelli, V Russo, C Rinaldi, O Di Giacinto, A Mauro and B Barboni \\ Department of Comparative Biomedical Sciences, University of Teramo, Piazza A. Moro, 45, 64100 Teramo, Italy
}

Correspondence should be addressed to A Martelli; Email: amartelli@unite.it B Barboni; Email: bbarboni@unite.it

\begin{abstract}
This research analyses how somatic and vascular compartments change during preantral follicle growth. To address this aim, theca-granulosa (somatic) proliferation indexes (PIs), proportion of proliferating endothelial cells (PE), vascular area (VA) and vascular endothelial growth factor A (VEGFA) expression were simultaneously recorded on single healthy preantral follicles, classified into six different stages on the basis of the diameter and the granulosa layers. An autonomous blood vessel network starts to appear only in class 3 . Vascular remodelling requires VEGFA expression, and VEGFA mRNA and VA significantly increase between class 3 and classes 4 and 5 and, further, in class 6 . In addition, a positive correlation exists between these parameters in classes 3-5. Despite variation in angiogenesis results from classes 3 to 5 , the statistical analysis reveals that the vascular parameters are positively and strictly correlated with somatic PIs. Conversely, class 6 , also characterized by higher values of somatic PIs, displays a stable proportion of PEs $(\cong \mathbf{4 0} \%)$ without showing any correlation among the different parameters analysed. To identify follicular subpopulations within different classes, a multivariate hierarchical cluster analysis was performed. This analysis reveals that the majority of classes 3 and 4 are quiescent follicles or structures that grow very slowly. Class 5 represents a transitory category, where half of the follicles maintain a low activity and the remaining express significantly higher levels of granulosa PI and VA. The follicles with this high activity are probably able to reach class 6 becoming dominant structures where somatic and vascular parameters are constantly on high levels and the VA remains the unique differentiating element.
\end{abstract}

Reproduction (2009) 137 45-58

\section{Introduction}

The regulation offolliculogenesis in the mammalian ovary is a complex process of cellular interactions able to create the local condition to sustain the development of a competent oocyte and the secretion of adequate steroids level in order to drive the reproductive cycle (Knight \& Glister 2006). Prior to puberty, as well as into more advanced reproductive age, most of the follicles are primordial, and composed by an immature sized oocyte surrounded by a single layer of flattened granulosa cells. As a consequence of adequate stimuli, the primordial structures are activated. The follicles entering into the growing phase are characterized by morphological and functional modifications (Gougeon 2004, Yang \& Fortune 2006).

The first phases of follicle growth can be divided into three distinct stages: activation of primordial follicles, transition from primary to preantral and from preantral to early tertiary/antral follicles (Fortune 2003). During these latter developmental phases, ovarian follicles become an active endocrine structure and sustain the growing phase of the oocyte that acquires the ability to undergo meiotic progression at the time of antral differentiation (Hunter et al. 2004, Knox 2005, Drummond 2006). Even if the process of follicle recruitment occurs cyclically, few of the growing ovarian structures physiologically reach the final stages, while the majority of them undergo a premature regression process known as atresia, which produces an irreversible and progressive loss of germ cells (Gougeon 2004).

The mechanisms involved in ovarian follicle recruitment and regression are only partially known, in particular those that regulate the early stages of folliculogenesis. Nevertheless, interest in this field has increased as the use of the pool of immature follicles is considered as a strategy to improve the efficiency of the assisted reproductive technologies (Fortune 2003).

The development of immature follicles is modulated by a variety of autocrine, paracrine and endocrine signals (Erickson \& Danforth 1995). In addition, morphological adjustments of the vascular supply may be crucial to regulate follicle growth and differentiation, although such a cause effect has yet to be established (Redmer \& Reynolds 1996, Barboni et al. 2000, Berardinelli et al. 2002). In particular, during the final antral stages, follicle growth is coupled with an increased blood vessel area (Barboni etal. 2004), close to ovulation, changes its organization into a mature vascular network (Martelli et al. 2006). In fact, until the periovulatory phase, the vascular network is 
represented by capillaries that, a few hours before ovulation, become covered by pericytes, and new large blood vessels appear in the follicular wall (Zimmermann et al. 2003, Martelli et al. 2006). The acquisition of a specific vascular supply seems to represent a limiting step in the selection of a dominant follicle destined to ovulation (Mattioli et al. 2001, Stouffer et al. 2001), while its disappearance is correlated with the process of early follicular atresia (Moor \& Seamark 1986).

The ovarian follicle has an active role in the process of capillary remodelling by producing several angiogenic factors. In particular, the vascular endothelial growth factor A (VEGFA) seems to play a major role in ovarian angiogenesis as demonstrated recently by several pieces of evidence (Wulff et al. 2001, 2002, Zimmermann et al. 2003, Kaczmarek et al. 2005, Shimizu \& Sato 2005, Abramovich et al. 2006, Shimizu 2006). Even if relevant progress has been made in understanding the mechanisms involved in the angiogenic events during the dominant final phase of tertiary follicle development (Fraser 2006, Martelli et al. 2006), the role of blood vessel remodelling in early follicular stages is unclear. In regard to preantral follicles, different reports indicate that these are able to synthesize VEGFA and are sensitive to its stimulatory effect (Danforth et al. 2003). Analogously, the VEGFA stimulatory effect is indirectly confirmed by the immunoneutralization experiments where a decrease in theca cell proliferation and a reduction in the endothelial cell area in late preantral follicles were observed (Wulff et al. 2002).

Starting from this limited information on the functional correlation existing between the vascular remodelling and the preantral follicle development, the present research has been designed to determine how follicular and vascular morphological parameters change during preantral follicle growth. To address this aim, several parameters such as granulosa, theca and endothelial cell proliferation, vascular area (VA), and VEGFA intrafollicular distribution have been studied. These analyses were simultaneously performed on single preantral follicles that were previously classified on the basis of the morphological stage of development (Morbeck et al. 1992). The variables were then statistically evaluated to examine the relationship existing between the aboveexamined parameters and the different categories of preantral follicles. Moreover, the multivariate hierarchical cluster analysis was designed to identify subpopulations within each class of preantral follicle.

\section{Results}

\section{Preantral follicle morphological classification}

The present research was performed on healthy preantral follicles identified using haematoxylin and eosin (HE) and caspase-3 in situ TUNEL staining. Preantral follicles were definitively judged as healthy when they showed a regular shaped oocyte, surrounded by granulosa cells regularly apposed on an intact basement membrane, as well as granulosa cell nuclei without signs of pycnosis. Moreover, healthy preantral follicles were confirmed when less than $20 \%$ of the granulosa cells displayed signs of apoptosis, revealed by the simultaneous positivity for caspase-3 and nuclear fragmentation (data not shown). Follicles not fulfilling these criteria were classified as unsuitable for the analyses. Healthy preantral follicles were divided, as summarized in Table 1, into different classes on the basis of the follicular diameter, number of granulosa layers, oocyte diameter and, when present, theca layer thickness.

Class 1 preantral follicles did not display the theca compartment that started to be evident as an undifferentiated structure in a low percentage of class 2 preantral follicles $(<10 \%)$. In class 2 , the theca compartment was characterized by few connective cells aligned to each other and localized near to the basal lamina.

Theca compartment characterized by a well-distinguishable inner and outer layer started to appear in class $3(\cong 12 \%)$. All follicles belonging to classes $4-6$ showed a complete follicular morphological organization.

\section{Granulosa and theca proliferation index (PI)}

Class 1 and 2 preantral follicles rarely displayed Ki-67 immunopositive cells (data not shown). By contrast, Ki67 positive cells were variably recorded in preantral follicles from classes 3 to 6 (Table 2; Fig. $1 \mathrm{~A}$ and $\mathrm{A}^{\prime}$ ). The statistical analysis of granulosa and theca PI (percentage of $\mathrm{Ki}-67$ positive cells/total cells of each follicular compartment) did not reveal a Gaussian distribution. For this reason, the results were expressed as median ranging between 25 and $75 \%$, as summarized in Table 2 . Granulosa and theca PI of follicles from classes 3 to 5

Table 1 Pig preantral follicle classification.

\begin{tabular}{llccc}
\hline Class & Follicular diameter $(\mu \mathrm{m})$ & Granulosa layers & Oocytes diameter $(\mu \mathrm{m})$ & Number of follicles \\
\hline 1 & $<65$ & $1-2$ & $35-40$ & 94 \\
2 & $>65-110$ & $2-4$ & $41-50$ & 53 \\
3 & $>111-180$ & $5-7$ & $51-55$ & 47 \\
4 & $>181-240$ & $8-10$ & $56-70$ & 42 \\
5 & $>241-300$ & $11-13$ & $71-80$ & 44 \\
6 & $>300$ & $>13$ & $81-100$ & $11-13$ \\
\hline
\end{tabular}


Table 2 Somatic (granulosa and theca) proliferation index (PI), vascular area (VA), vascular endothelial growth factor A (VEGFA) mRNA and proportion of proliferating endothelial cells (PE/PT) recorded in the considered classes of pig preantral follicles.

\begin{tabular}{|c|c|c|c|c|c|}
\hline & Classes & Somatic PI (\%) & VA $\left(\mu \mathrm{m}^{2} /\right.$ field $)$ & VEGFA mRNA $(n$ cells/field) & PE/PT (\%) \\
\hline \multirow[t]{2}{*}{3} & Granulosa & $12.50(4.71-22.61)$ & & $18.11(3.51-27.52)^{*}$ & \\
\hline & Theca & $3.41(1.32-7.21)$ & $283.01(102.25-548.75)^{*}$ & $2.01(1.21-8.62)$ & $50.00(32.50-60.00)$ \\
\hline \multirow[t]{2}{*}{4} & Granulosa & $12.55(2.87-17.77)$ & & $40.52(9.02-46.75)^{\dagger}$ & \\
\hline & Theca & $5.41(0.70-9.61)$ & $501.21(365.21-702.12)^{+}$ & $4.25(2.53-8.06)$ & $42.50(0.00-53.75)$ \\
\hline \multirow[t]{2}{*}{5} & Granulosa & $12.61(2.72-15.67)$ & & $41.52(8.25-56.03)^{+}$ & \\
\hline & Theca & $2.01(0.51-4.32)$ & $432.24(252.51-715.25)^{\dagger}$ & $4.89(2.45-11.25)$ & $37.50(0.00-50.00)$ \\
\hline \multirow[t]{2}{*}{6} & Granulosa & $18.25(9.72-23.92)^{*}$ & & $92.51(68.25-94.64)^{\ddagger}$ & \\
\hline & Theca & $4.91(2.85-9.85)^{*}$ & $1023.56(749.51-1466.54)^{\ddagger}$ & $9.51(8.74-13.22)^{\S}$ & $40.00(35.00-45.00)$ \\
\hline
\end{tabular}

The values are expressed as median between the 25 and $75 \%$, since all values did not display a Gaussian distribution. ${ }^{*, t, \neq, \S}$ Values with different superscripts within each column of parameters indicate data significantly different at least for $P<0.05$. Granulosa and theca values were compared separately.

showed a similar median distribution $(P>0.05)$ that became significantly higher $(P<0.05)$ in class 6 preantral follicles.

\section{von Willebrand factor (VWF) and VA}

A specific follicular blood vessel network, identified with the endothelial marker $v W F$, started to appear in class 3 when preantral follicles had more than four granulosa layers, class 3 and 4 preantral follicles displayed small capillaries scattered within the follicular wall (Fig. $1 \mathrm{~A}$ and $\left.A^{\prime}\right)$. While a specific blood vessel network localized close to the basal membrane, characterized by small vessels, started to appear in classes 5 and 6 (Fig. 1A and $\mathrm{A}^{\prime}$ ). In addition, in the outer theca of class 6 preantral follicles, some large blood vessels were recorded (Fig. 1 $\mathrm{A}^{\prime}$ ).

VA ( $v W F$ positive area/10 $\left.000 \mu \mathrm{m}^{2}, \mathrm{VA}\right)$ did not follow a Gaussian distribution and for this reason has been expressed as median values (Table 2). Two significant increases in the VA were observed during preantral follicle development: first during the transition from class 3 to classes 4 and 5 , and then from classes 4 and 5 to class $6(P<0.05)$.

\section{VEGFA mRNA expression and VEGFA protein localization}

A few somatic cells hybridized for VEGFA mRNA were occasionally observed in class 1 and 2 preantral follicles (data not shown). By contrast, VEGFA mRNA hybridization was regularly observed in cells from class 3 follicles (Fig. 1B and $\mathrm{B}^{\prime}$ ).

The median of VEGFA mRNA (percentage of hybridized cells) in granulosa and theca cells of preantral follicles significantly increased during the transition from class 3 to classes 4 and $5(P<0.05)$. Moreover, a further significant increase in VEGFA mRNA was then recorded in class 6 both in granulosa and theca cells (Table 2; $P<0.05$ ).

A limited and irregular VEGFA immunostaining was observed in follicles of classes 1 and 2 (data not shown). VEGFA positivity, even if highly variable, involved several cells of theca and granulosa compartment of class 3-5 preantral follicles (Fig. 1C and C'). By contrast, all class 6 preantral follicles displayed a high immunopositivity for VEGFA protein. Analysing the global VEGFA pattern in each preantral follicle, it has been observed that there is a positive link between VEGFA mRNA and protein. In fact, on the same follicle and on sequential sections of class 3-5 preantral follicles when the transcript was observed, also the protein of the angiogenic factor was expressed, while in the absence of VEGFA mRNA, there was no immunopositivity for the protein. By contrast, all class 6 preantral follicles showed both VEGFA mRNA and protein (Fig. $1 \mathrm{~B}^{\prime}$ and $\mathrm{C}^{\prime}$ ). As in preantral follicles, an analogous VEGFA mRNA and protein expression was also recorded in the oocyte (Fig. $1 \mathrm{~B}^{\prime}$ and $\mathrm{C}^{\prime}$ ). VEGFA oocyte expression was confirmed by immunoblot and RT-PCR analyses performed on a pool of oocytes collected from preantral follicles of different classes (Fig. 2).

\section{Proliferating endothelial cells/proliferating thecal cells (PE/PT)}

A double immunostaining for Ki-67 and vWF (Fig. 1A') was performed to calculate the PE/PT. The quantification of the PE/PT within the different classes of preantral follicles is summarized in Table 2 . In classes 3-5, only some preantral follicles ( $n=10,11$, and 20 respectively) showed no PEs. By contrast, all class 6 preantral follicles showed PEs. The statistical analysis did not show any significant differences in the PE/PT among all follicular classes considered $(P>0.05)$.

\section{Correlation between follicular developmental parameters}

A correlation test was carried out to assess how the parameters considered above were related to each other within the different classes of preantral follicles. As summarized in Table 3, the statistical analysis revealed that in classes 3-5, there was a positive correlation between all parameters considered, both in granulosa and in theca compartment $(P<0.05$ or $P<0.01)$. However, these correlations were lost in class $6(P>0.05)$. 

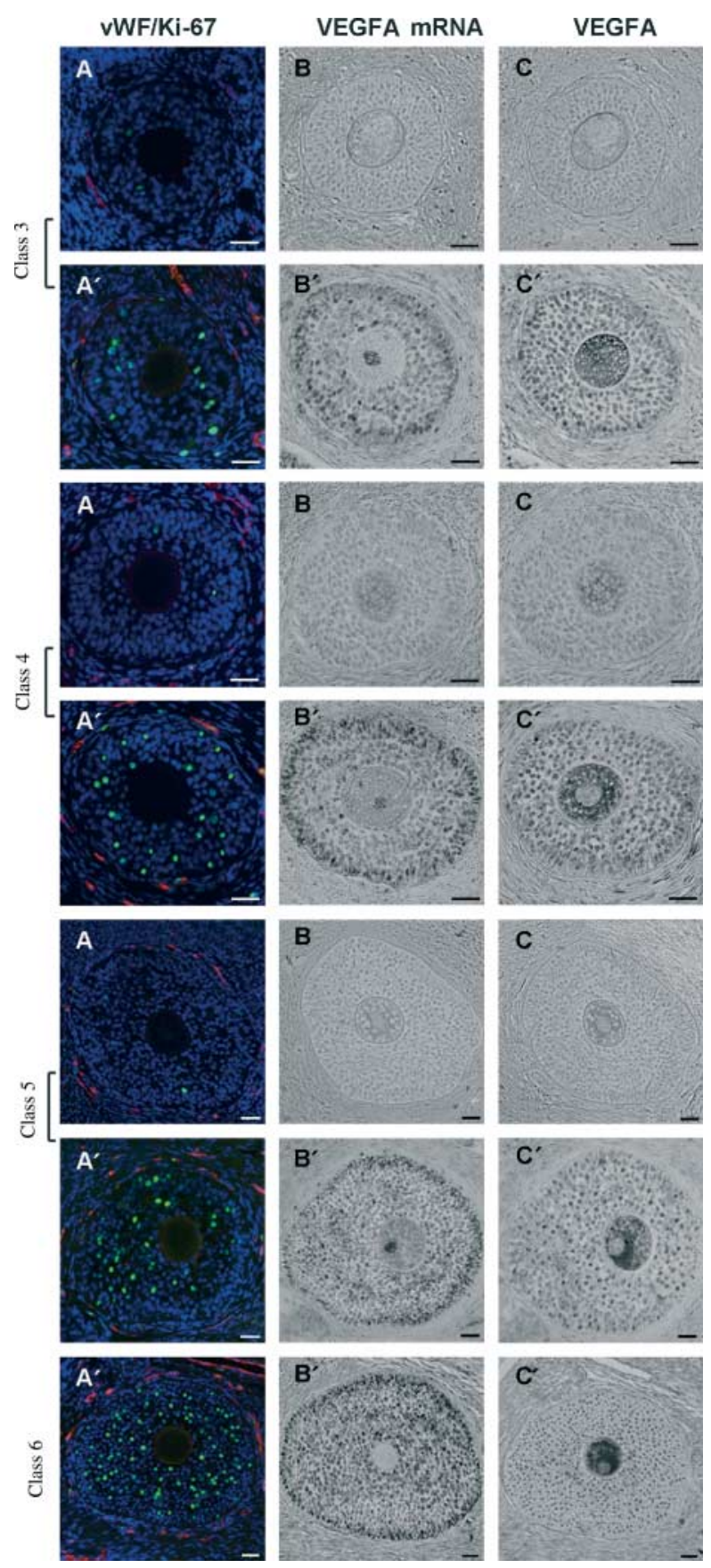

Figure 1 Representative micrographs of single pig healthy preantral follicle sections belonging to the different classes (from 3 to 6) considered. Left panel $\left(A\right.$ and $A^{\prime}$ ): intrafollicular distribution of $\mathrm{VWF}$ (red stain) and Ki-67, a cellular proliferative marker (green stain), were revealed using a double immunohistochemical technique. The cell nuclei were counterstained with DAPI (blue stain) to visualize the tissue morphology and to identify the follicular compartments. Middle panel $\left(\mathrm{B}\right.$ and $\mathrm{B}^{\prime}$ ): in situ hybridization is shown to evaluate the intrafollicular distribution of the VEGFA mRNA. Right panel ( $C$ and $C^{\prime}$ ): location of the VEGFA protein within the follicular and germinal compartments. For the classes 3-5, two different examples were given: the three panels on the top $(\mathrm{A}, \mathrm{B}$ and $\mathrm{C})$ and bottom $\left(\mathrm{A}^{\prime}, \mathrm{B}^{\prime}\right.$ and $\left.\mathrm{C}^{\prime}\right)$ display respectively the sequential sections of a representative follicle with low and high activity. Bar $=30 \mu \mathrm{m}$.

\section{Cluster analysis of preantral follicles}

By evaluating the distribution of the different parameters recorded for each follicle analysed, multivariate hierarchical analysis revealed several subpopulations within each preantral follicle class (Figs 3 and 4). All classes of follicles could be divided into two subpopulations ( 1 and 2) that differed significantly for somatic $\mathrm{PI}, \mathrm{VA}$ and granulosa/theca VEGFA mRNA $(P<0.01)$ and PE/PT for class $5(P<0.01)$.

The subpopulations 1 and 2 of classes 3 and 4 (Fig. 3) could be subsequently divided into four subpopulations ( $1 \mathrm{a}$ and $1 \mathrm{~b}, 2 \mathrm{a}$ and $2 \mathrm{~b}$ ). The first two subpopulations (1a and $1 \mathrm{~b})$ differed significantly for somatic $\mathrm{PI}(P<0.01$ for class 3 and $P<0.05$ for class 4$)$, VA $(P<0.01)$ and granulosa/theca VEGFA mRNA $(P<0.01)$. The other two subsets $(2 \mathrm{a}$ and $2 \mathrm{~b})$ were significantly different $(P<0.01)$ only for the VA.

Preantral follicles of class 5 (Fig. 4) showed a complex variety of subpopulations. Subpopulations $1 \mathrm{a}$ and $1 \mathrm{~b}$ were different in terms of theca $(P<0.05)$, granulosa PI $(P<0.01)$, VA $(P<0.01)$ and granulosa/theca VEGFA mRNA $(P<0.05)$. Subpopulations $2 \mathrm{a}$ and $2 \mathrm{~b}$ differed in terms of granulosa $\mathrm{PI}(P<0.01)$ and VA $(P<0.01)$ Moreover, the subpopulation 1 a could be further divided into $1 \mathrm{a}^{\prime}$ and $1 \mathrm{a}^{\prime \prime}$ on the basis of somatic $\mathrm{PI}(P<0.05), \mathrm{VA}$ $(P<0.01)$ and VEGFA mRNA $(P<0.05$ for theca and $P<0.01$ for granulosa). The subpopulation 2a generated two other subpopulations $2 \mathrm{a}^{\prime}$ and $2 \mathrm{a}^{\prime \prime}$ with differing granulosa PI $(P<0.01)$ and VA $(P<0.01)$.

Finally, it was possible to recognize in class 6 preantral follicles (Fig. 4) four subpopulations (1a and 1b, 2a and $2 \mathrm{~b})$ that were significantly different only for VA $(P<0.01)$.

The dendrograms allowed the building of a model that describes the different subpopulations within each class of preantral follicles. As shown in Fig. 5, this model ordinates in a one-dimensional space the subpopulations using the distances between the bifurcations inside the dendrograms, which are proportional to the homologies between the subpopulations themselves.

\section{Discussion}

The present research analyses how important parameters of the somatic and vascular compartment change during the process of preantral follicle growth. To achieve this aim, somatic index $(\mathrm{PI})$, proportion of PEs (PE/PT), VA and VEGFA expression (VEGFA mRNA and protein) were simultaneously recorded on single healthy preantral follicles classified into six different stages of development as proposed by Morbeck et al. (1992). This precise morphological classification was adopted to better interpret the data obtained, distinct from other studies where preantral follicles were considered as early or late structures when the granulosa compartment was 
(a) Western blot

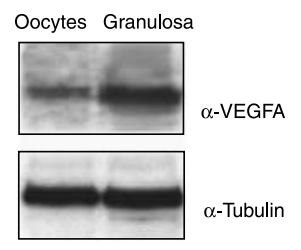

(b) RT-PCR

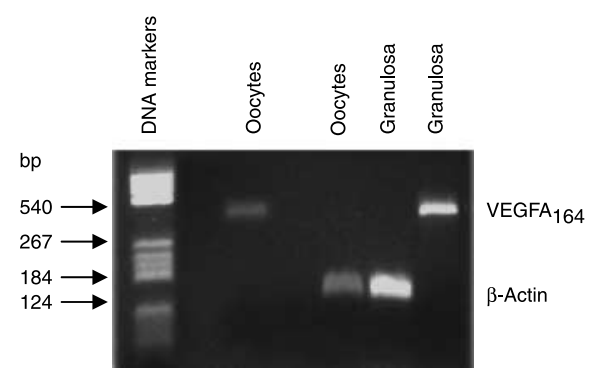

Figure 2 VEGFA expression, protein and mRNA, within oocytes collected from preantral follicles of classes 3-6. (A) An example of a western blot analysis and (B) a representative RT-PCR experiment performed on a pool of oocytes (150 germinal cells) isolated from different classes of preantral follicles. Granulosa cells were used during the western blot and RT-PCR experiments (three replicates each) as positive control.

organized in less or more than four granulosa layers respectively (Wulff et al. 2002, Danforth et al. 2003, Roberts et al. 2007).

The present study shows that an autonomous vascular supply starts to be evident in preantral follicles of class 3 , while the structures belonging to classes 1 and 2 do not receive a specific trophic vascular supply from the blood vessels within the surrounding stroma. The data obtained, moreover, seem to confirm that the organization of an individual capillary network, during preantral follicle growth, requires the local synthesis of VEGFA to stimulate and drive follicular vascular remodelling (Kaczmarek et al. 2005). In fact, while VEGFA expression was occasionally observed in the follicles of classes 1 and 2, on the contrary, it was always detected in preantral follicles during the late stages of development. Furthermore, the analysis of VEGFA expression revealed that the angiogenic stimulus progressively increases from class 3 to classes 4 and 5, reaching its highest levels during the final stage of development (class 6). The theca VEGFA mRNA that appeared low in preantral follicles from classes 3 to 5 becomes significantly higher in class 6 , when a parallel increase in the VA was recorded. Stable and high levels of VEGFA expression both in the theca and in granulosa compartments characterizes the final stage of preantral follicle development when the follicular walls are colonized by a widespread capillary network near the basal membrane and high levels of angiogenic factors may be required to maintain and stabilize these immature blood vessels (Carmeliet et al. 1996, Ferrara 1996, Ferrara \& Davis-Smyth 1997). In addition, high levels of VEGFA appeared within the follicular structure just before the process of antrum formation. In this context, microvessel permeability may be imposed by VEGFA to stimulate plasma extravasations allowing the accumulation of fluids within the differentiating follicular cavity (Isobe et al. 2005).

The VEGFA within preantral follicles also seems to be dependent on the oocyte in order to express and synthesize the angiogenic factor. Similar to other molecules, VEGFA could be included among the signals involved in the bidirectional control of oocyte-follicle function (Diaz et al. 2007, Hutt \& Albertini 2007), by guaranteeing that follicle development can be synchronized with the growth of the metabolically active germinal cells. Even if it has been demonstrated that there are also post-transcriptional and post-translational mechanisms involved in VEGFA expression in the ovary and other tissues (Hazzard et al. 1999, Neufeld et al. 1999, Martelli et al. 2006), in this research all preantral follicles showed a relationship between VEGFA mRNA and protein production. In fact, the follicles and the oocytes that expressed the transcript were also positive

Table 3 Coefficients of correlation recorded between the somatic (granulosa and theca proliferation index (PI)) and vascular (vascular endothelial growth factor A (VEGFA) mRNA, vascular area (VA) and proliferating endothelial cells/proliferating thecal cells (PE/PT)) parameters recorded in granulosa and theca compartments of the considered classes of pig preantral follicles.

\begin{tabular}{lcccc}
\hline Granulosa & Class 3 & Class 4 & Class 5 & Class 6 \\
\hline PI versus VA & $0.786(P<0.01)$ & $0.730(P<0.01)$ & $0.886(P<0.01)$ & $0.256(P>0.05)$ \\
PI versus VEGFA mRNA & $0.911(P<0.01)$ & $0.868(P<0.01)$ & $0.866(P<0.01)$ & $0.263(P>0.05)$ \\
VA versus VEGFA mRNA & $0.785(P<0.01)$ & $0.644(P<0.01)$ & $0.796(P<0.01)$ & $0.328(P>0.05)$ \\
PE/PT versus PI & $0.762(P<0.01)$ & $0.487(P<0.05)$ & $0.792(P<0.01)$ & $0.205(P>0.05)$ \\
PE/PT versus VEGFA mRNA & $0.689(P<0.01)$ & $0.523(P<0.01)$ & Class 5 & $0.030(P>0.05)$ \\
\hline Theca & Class 3 & Class 4 & $0.918(P<0.01)$ & $0.308(P>0.05)$ \\
\hline PI versus VA & $0.798(P<0.01)$ & $0.729(P<0.01)$ & $0.919(P<0.01)$ & $0.282(P>0.05)$ \\
PI versus VEGFA mRNA & $0.873(P<0.01)$ & $0.913(P<0.01)$ & $0.792(P<0.01)$ & $0.090(P>0.05)$ \\
VA versus VEGFA mRNA & $0.739(P<0.01)$ & $0.740(P<0.01)$ & $0.523(P<0.05)$ & $0.201(P>0.05)$ \\
PE/PT versus PI & $0.473(P<0.05)$ & $0.486(P<0.05)$ & $0.782(P<0.01)$ & $0.080(P>0.05)$ \\
PE/PT versus VA & $0.449(P<0.05)$ & $0.419(P<0.05)$ & $0.785(P<0.01)$ & $0.248(P>0.05)$ \\
PE/PT versus VEGFA mRNA & $0.480(P<0.05)$ & $0.524(P<0.05)$ & & \\
\hline
\end{tabular}




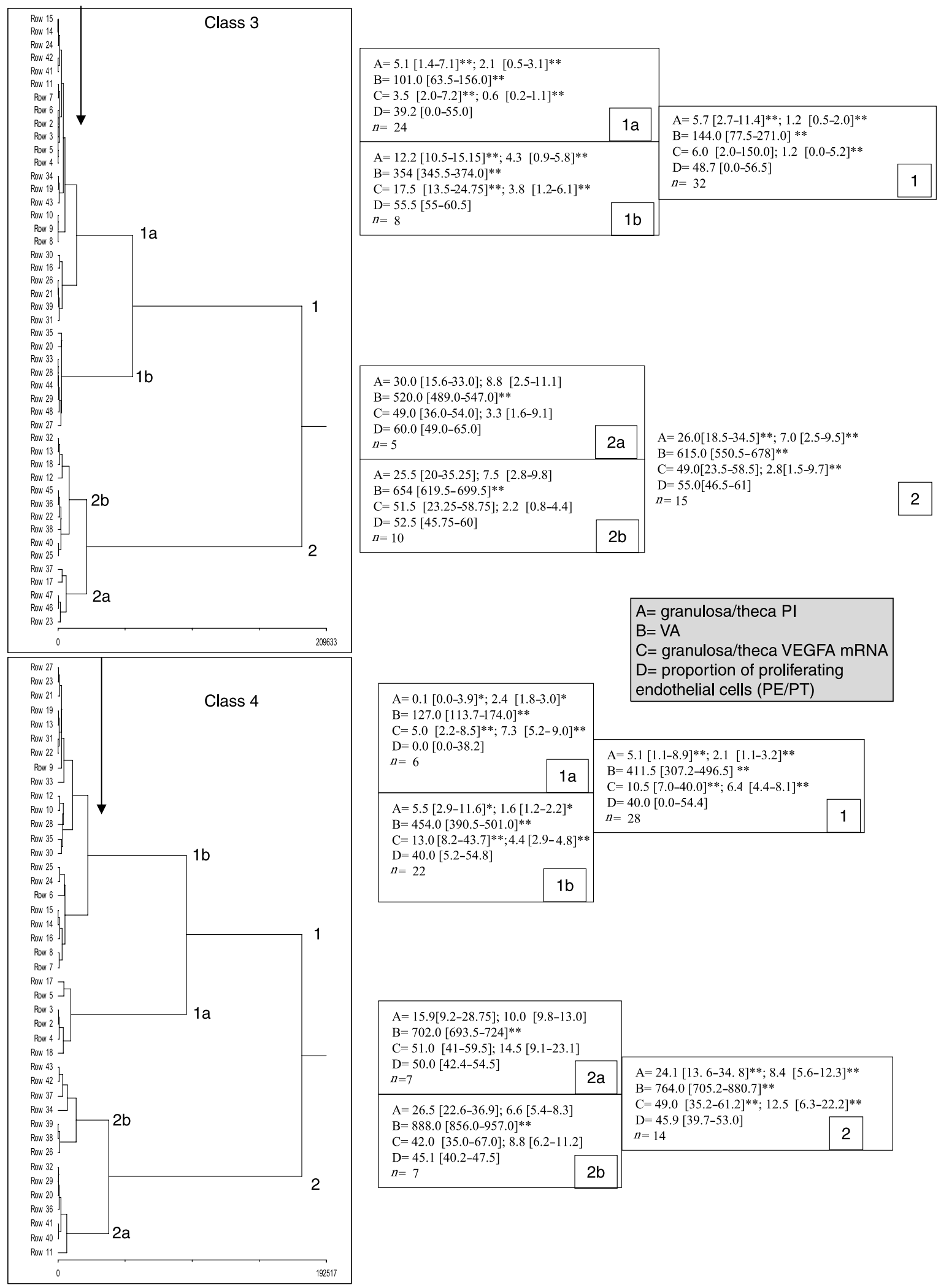

Figure 3 Dendrograms derived from cluster analysis of the data obtained on single follicles of classes 3 and 4 . The cutting values (arrows) were determined evaluating the statistically differences among the examined parameters. A, granulosa/theca Pl; B, VA; C, granulosa/theca VEGFA mRNA; D, proportion of proliferating endothelial cells (PE/PT); ${ }^{* * *}$ Significantly different values for $P<0.05$ and $P<0.01$ respectively. 

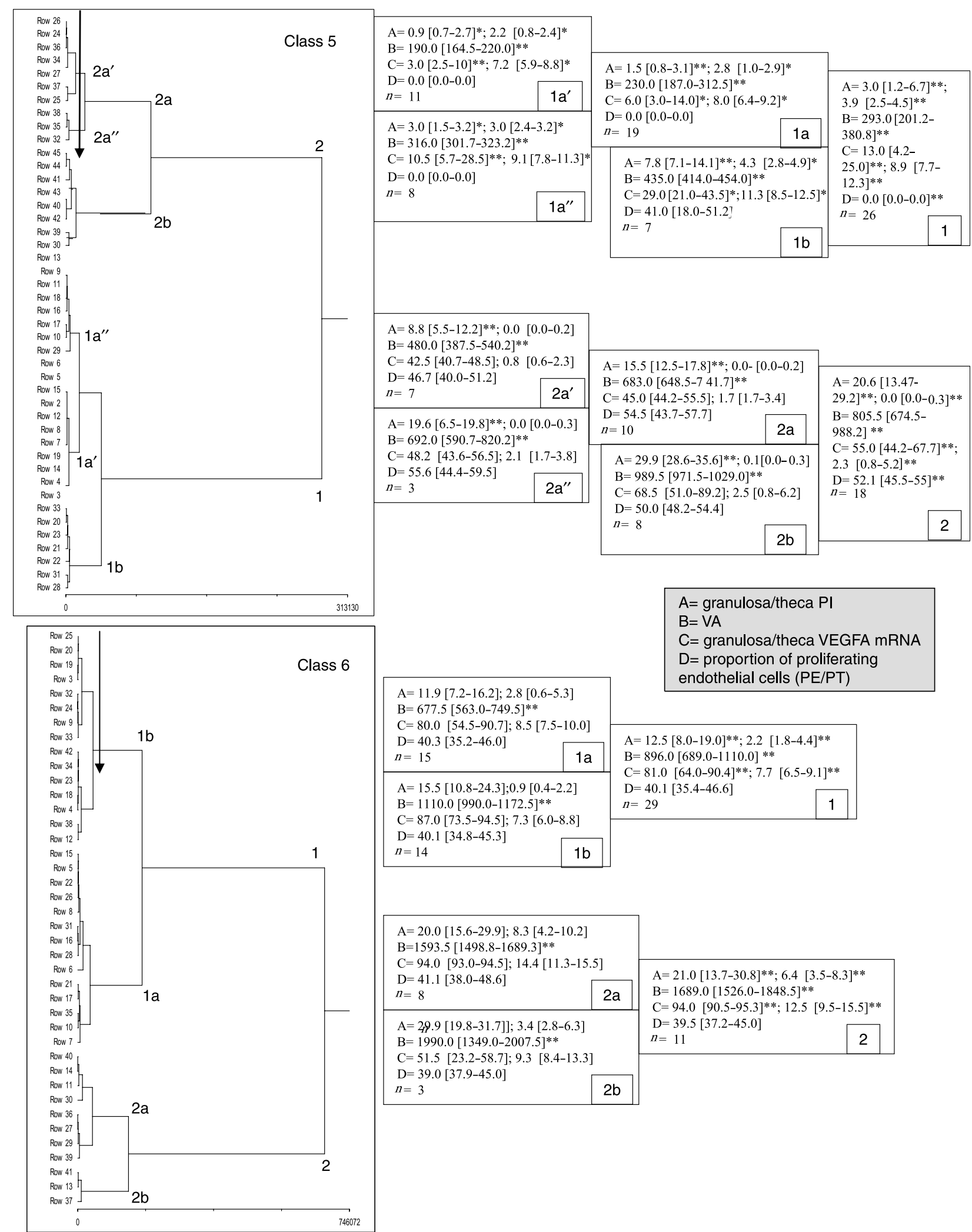

\section{$A=$ granulosa/theca $P I$ $\mathrm{B}=\mathrm{VA}$ \\ $\mathrm{C}=$ granulosa/theca VEGFA mRNA $\mathrm{D}=$ proportion of proliferating endothelial cells (PE/PT)}

$\mathrm{A}=11.9[7.2-16.2] ; 2.8[0.6-5.3]$ $\mathrm{B}=677.5[563.0-749.5]^{* *}$

$\mathrm{C}=80.0[54.5-90.7] ; 8.5$ [7.5-10.0]

$\mathrm{D}=40.3[35.2-46.0]$

\begin{tabular}{l|c|}
$\mathrm{D}=40.3[35.2-46.0]$ & $1 \mathrm{a}$ \\
$n=15$ &
\end{tabular}

$\mathrm{A}=15.5$ [10.8-24.3];0.9 [0.4-2.2]

$\mathrm{B}=1110.0[990.0-1172.5]^{* *}$

$\mathrm{C}=87.0$ [73.5-94.5]; $7.3[6.0-8.8]$

$\mathrm{D}=40.1[34.8-45.3]$

$n=14$

\begin{tabular}{l|l}
$\mathrm{D}=40.1[34.8-45.3]$ \\
$n=14$ & $1 \mathrm{~b}$
\end{tabular}

$\mathrm{A}=12.5[8.0-19.0]^{* *} ; 2.2[1.8-4.4]^{* *}$

$\mathrm{B}=896.0[689.0-1110.0] * *$

$\mathrm{C}=81.0[64.0-90.4]^{* *} ; 7.7[6.5-9.1]^{* *}$ $\mathrm{D}=40.1[35.4-46.6]$

$n=29$

1

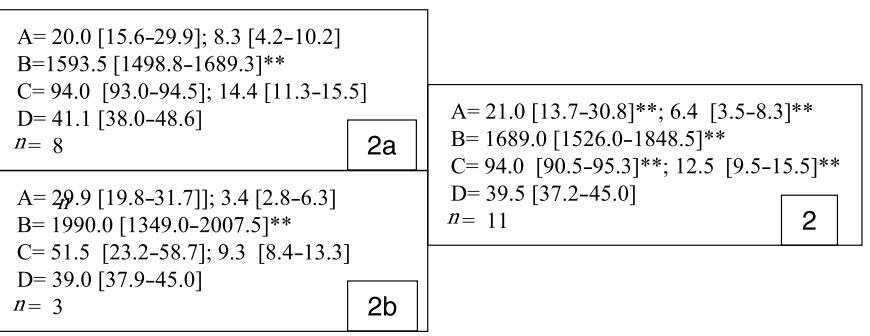

Figure 4 Dendrograms derived from cluster analysis of the data obtained on single follicles of classes 5 and 6 . The cutting values (arrows) were determined evaluating the statistically differences among the examined parameters. A, granulosa/theca Pl; $\mathrm{B}, \mathrm{VA} ; \mathrm{C}$, granulosa/theca VEGFA mRNA; $\mathrm{D}$, proportion of proliferating endothelial cells (PE/PT). ${ }^{*}, *$ Significantly different values for $P<0.05$ and $P<0.01$ respectively. 


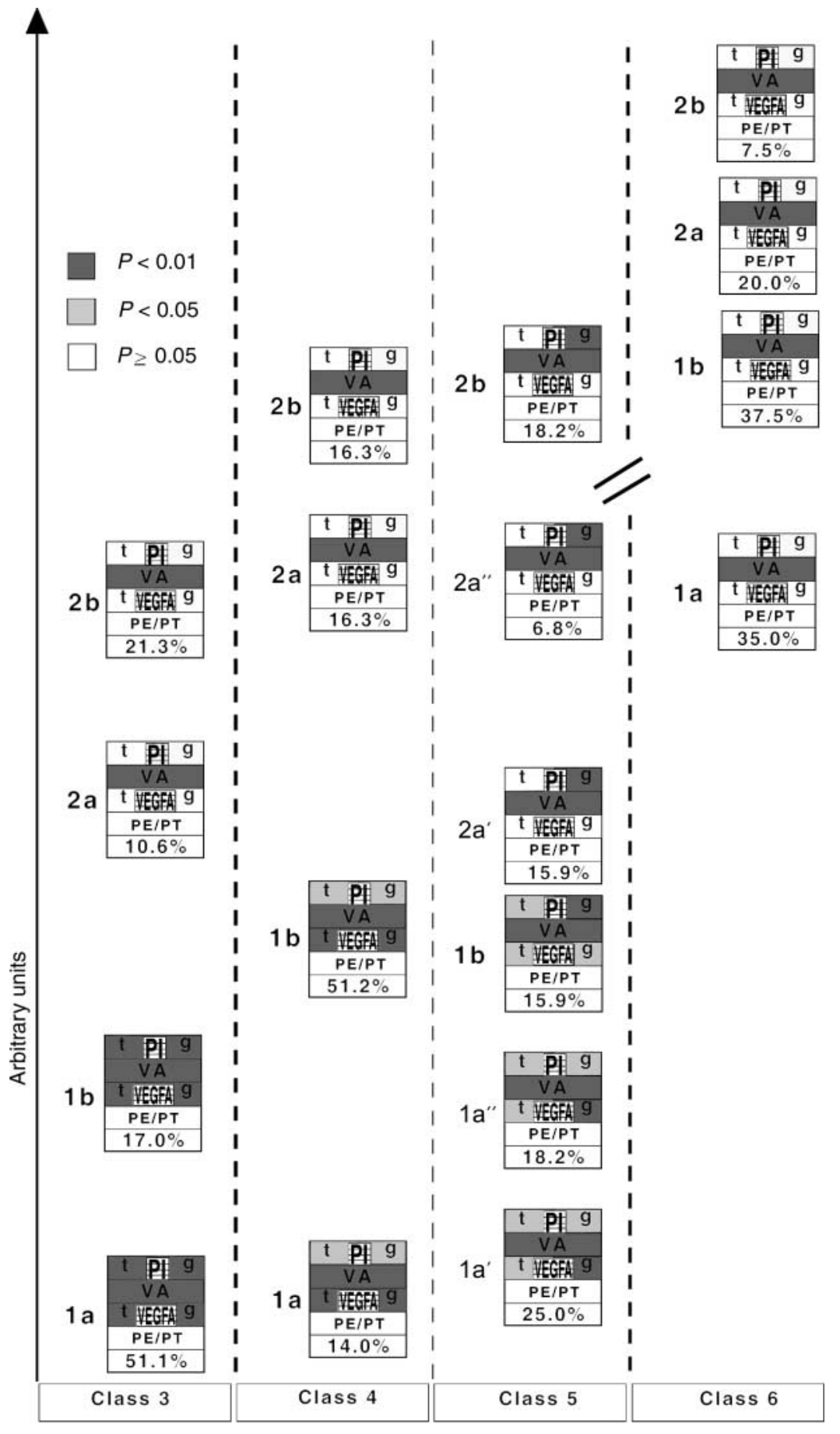

Figure 5 A general model that describes the distribution of the follicular subpopulations identified inside each follicular class by using cluster analysis. The subpopulations were represented within each class and arranged on the $y$-axis by considering the distances between the bifurcation obtained in the dendograms. The grey scale represents significant differences recovered for somatic and vascular parameters. The thickness of the dotted line represents the statistical difference among classes. $\mathrm{PI}$, theca proliferation index; $\mathrm{g} \mathrm{Pl}$, granulosa proliferation index; $\mathrm{VA}$, vascular area; $\mathrm{t}$ VEGFA, theca VEGFA mRNA; g VEGFA, granulosa VEGFA mRNA; PE/PT, proportion of proliferating endothelial cells; \% value, percentage of preantral follicles belonging to the subpopulation. to the related protein. By contrast, preantral follicles that were characterized by the absence of VEGFA mRNA were also negative to the protein.

Follicular angiogenesis in classes 3-5 preantral follicles was quite variable. In fact, some structures did not display PEs ( $\cong 21,26$ and $45 \%$ in classes 3,4 and 5 respectively), while, in the remaining follicles belonging to these classes, the incidence of mitosis within the endothelial cells ranged between 30 and $60 \%$. These data suggest that the follicular angiogenesis in classes 3-5 could be in switch-off or switch-on position in response to specific stimuli. On the contrary, when preantral follicles reached the late stage of growth (class 6), probably under the stimulus of high and stable levels of VEGFA, angiogenesis remained active and the proportion of PEs was high.

These results seem to be in agreement with the recent experiments of Yang \& Fortune (2007) showing that in 
vitro VEGFA is able to stimulate the early preantral follicles but is totally ineffective on the progression of the later ones, even after long periods of culture.

Interpreting the results of the correlation analysis between all the vascular parameters recorded (VEGFA mRNA, VA and proportion of PEs) and the somatic PI in classes 3-5, it could be hypothesized that the small (classes 3 and 4) and middle (class 5) preantral structures are divided into two sets of follicles: one able to increase its vascular network, and another one inactive in terms of angiogenesis and is quiescent.

On the basis of these data, it could be concluded that the process of angiogenesis, also during the preantral stage of folliculogenesis, appears crucial to sustain the increasing metabolic requirements during the process of growth. In addition, other new roles for the PEs could be supposed (Lammert et al. 2001, Roberts et al. 2007). Recently, endothelial cells and nascent vessels have been directly associated with the growth and differentiation of tissues/organs providing growth and/or morphogenetic signals (Lammert et al. 2001). Part of this vascular influence seems to be mediated by the VEGFA itself that was hypothesized to have a direct effect on non-vascular elements in a variety of tissues, including the ovary (Roberts et al. 2007). The strict correlation observed between somatic and vascular parameters may represent additional evidence that VEGFA may be capable of direct stimulation of the somatic components, over its indirect influence on follicular development through the control of vascular physiology (Otani et al. 1999, Danforth et al. 2003, Abramovich et al. 2006).

The positive correlation existing between the morphological and vascular parameters disappeared in preantral follicles of class 6, when somatic PI and the angiogenic functions (VEGFA expression, VA and PE/PT) remained at high and stable levels. The high somatic and vascular parameters recorded in class 6 preantral follicles, which differentiates this late stage of growth from all the earlier ones, may be explained by considering previous evidence demonstrating that during this final stage of secondary follicle development sensitivity to the FSH occurs (Sicinski et al. 1996, McGee et al. 1997, McGee \& Hsueh 2000).

Furthermore, the data obtained identified the VA as the crucial parameter that is essential to discriminate between growing preantral follicles. In fact, the VA initially increased when follicles passed from class 3 to classes 4 and 5 and then during the late stage of growth (class 6). Thus, the first enhancement in the VA may be necessary to sustain the increased requirements in nutrients and gases in growing structures, while the second increase may guarantee the major delivery of endocrine and paracrine molecules that metabolically change and drive the function of late preantral follicles (Fortune 2003, Gougeon 2004).
The cluster analysis that aggregates the preantral follicles on the basis of reciprocal similarity allowed the building of dendrograms (Figs 3 and 4) representing the data subsets inside each follicular class considered. The statistical analysis stated that this articulation was not a consequence of a mathematical artefact, but that the biological parameters really differed among follicle subpopulations. This statistical technique leads to the establishment of a model representing preantral follicle development (Fig. 5). This model showed that the majority of the small preantral follicles (classes 3 and 4) are present in the ovary as quiescent structures $(\cong 70 \%$ ), or as active follicles that start their growth slowly. In particular, the small active preantral follicles had differing VA, indicating that the extension of the blood vessel network may become the crucial element for the follicles that are recruited to growth. Class 5 represents a transitory category between the earlier (classes 3 and 4) and later (class 6) stage of preantral development. Half of the class 5 follicles maintain a very low activity similar to that recorded in classes 3 and 4, but the remaining follicles express high levels of granulosa PI and VA. These results suggest that in the preantral follicles of class 5 with a higher activity a simultaneous contribution of the somatic and vascular component is required within this class of preantral follicles to guarantee the progression of the follicles towards the final stages of development. In fact, when the follicles enter into class 6 (subpopulation 1a: $35 \%$ of follicles) somatic and vascular parameters appear similar to that observed in class 5 preantral follicles showing the highest activity. Class 6 follicles (large follicles) maintained constant high level of somatic and vascular parameters with the proportion of PEs at stable high levels appearing as definitively selected structures. In particular, the class 6 differential element was the VA that is the crucial and often the unique parameter that accompanied the final process of growing in the majority of the stages of preantral follicle development. Hence, the progressive increase in the VA represents the final element of differentiation among the subpopulations in the different stages of preantral follicles, and in those that reach the late stage of development where it is probably required to sustain the process of antrum differentiation.

In conclusion, the classification obtained in the present research permits division of preantral follicles into three different stages (early, mid and late) superimposing the morphological parameters proposed by Fortune (2003) with the developmental parameters analysed in this research. It is known that under physiological conditions, preantral follicle growth occurs within a rich milieu of endocrine, paracrine and autocrine factors (Kotsuji \& Tominaga 1994, Gelety \& Magoffin 1997). As a consequence, it may be hypothesised that the availability of an adequate vascular supply providing adequate levels of endocrine and paracrine signals may play a key role in follicle selection 
during preantral follicle growth (Danforth 1995, Hull et al. 2003, Roberts et al. 2007). In conclusion, the data presented suggest that preantral follicles appear as autonomous units engaged in a competition for growth, where the vascular supply represents a crucial prerequisite for the development and selection.

\section{Materials and Methods}

\section{Tissue collection and experimental protocols}

Swine ovaries in the luteinic phase of the reproductive cycle were collected at the local slaughterhouse. Once in the laboratory, each ovary was divided into three to five portions. One part was used to mechanically isolate preantral follicles for the biochemical investigations, and the other portions were immediately fixed in $4 \%$ paraformaldehyde/PBS $(\mathrm{pH} 7.4)$ for $12 \mathrm{~h}$ at $4{ }^{\circ} \mathrm{C}$. After dehydration, each tissue sample was embedded in paraffin wax and serially sectioned at $5 \mu \mathrm{m}$ thickness.

All the follicular sections of each preantral follicle were collected on poly-L-lysine-coated slides (Sigma) and then sequentially processed for $\mathrm{HE}$, immunohistochemical and in situ hybridization analyses. In detail, each preantral follicle was used to perform, at least in double, the following morphological analyses:

a) caspase-3 and in situ TUNEL to distinguish between atretic and healthy follicles (Berardinelli et al. 2004);

b) $v W F$ to identify the endothelial cells and to quantify the extension of the VA (Barboni et al. 2004, Martelli et al. 2006);

c) Ki-67 antigen, a cell proliferation marker, to quantify the degree of mitotic granulosa, theca and endothelial cells (Martelli et al. 2006);

d) VEGFA protein to describe the intrafollicular distribution of the angiogenic factor (Martelli et al. 2006) and

e) VEGFA mRNA detected by in situ hybridization (Barboni et al. 2004, Martelli et al. 2006).

The morphological analyses were performed with an Axioskop 2 Plus epifluorescence microscope (Zeiss, Oberkochen, Germany) equipped with a cooled colour chargecoupled device camera (AxioVision Cam, Zeiss) interfaced to a computer workstation and provided with an interactive and automatic image analyser (AxioVision, Zeiss).

To exclude individual differences among animals, the follicles were collected from at least five different pigs.

\section{Identification and classification of preantral follicles}

Follicular stages were defined according to Wulff et al. (2001): primary follicles (containing only one granulosa cell layer), preantral follicles (more than two granulosa cell layers and no antrum) and early antral follicles (one or more fluid-filled spaces in the granulosa layer).

In this study, only healthy preantral follicles were analysed. Pig healthy follicles were identified combining the HE with the
caspase-3/TUNEL staining, according to Wulff et al. (2002) and Berardinelli et al. (2004).

On two or more HE sections, mean follicular diameter was calculated using the KS300 computed image analysis system (Zeiss), set to measure two diameters of the follicle/oocyte section at right angles and only symmetrical follicles (right angle cross sections within $10 \%$ of each other) were considered (Morbeck et al. 1992). Since in the early stages of preantral follicles the outer boundary of the theca layers could not be defined precisely, the follicular diameter was always measured from the basement membrane immediately outside the granulosa cells (Lundy et al. 1999, Griffin et al. 2006). When the theca compartment was clearly evident, it was outlined and the mean thecal thickness measured. In all sections of each preantral follicle analysed, the whole cross section was recorded and theca and granulosa compartments were outlined and examined separately. The morphometric parameters (follicle diameters and number of granulosa cell layers) were calculated by two investigators in a blinded fashion, and the correlation coefficient for follicle counts between the two investigators (Zimmermann et al. 2003) was 0.915. On the basis of mean follicular diameter and the number of granulosa layers, preantral follicles were classified into six different categories adopting, with minor modifications, the classification developed by (Morbeck et al. 1992)

- class 1: $<65 \mu \mathrm{m}$ and 1-2 layers of granulosa cells,

- class 2: from 65 to $110 \mu \mathrm{m}$ with 2-4 layers of granulosa cells,

- class 3: from 111 to $180 \mu \mathrm{m}$ with 5-7 layers of granulosa cells,

- class 4: from 181 to $240 \mu \mathrm{m}$ with 8-10 layers of granulosa cells,

- class 5: from 241 to $300 \mu \mathrm{m}$ with 11-13 layers of granulosa cells and

- class 6: follicular diameter $>300 \mu \mathrm{m}$ with $>13$ layers of granulosa cells.

At least, 40 healthy follicles were processed and analysed in each preantral follicle category considered.

\section{Immunohistochemistry}

\section{Caspase-3 and in situ TUNEL}

At least, two sections of each preantral follicle were simultaneously exposed to immunohistochemical analysis for the detection of the nucleosomal fragmentation and caspase-3 distribution (Berardinelli et al. 2004). According to Berardinelli et al. (2004), on the same section were applied the ApopTag in situ Apoptosis detection kit (Intergen Company, Oxford, UK), and a rabbit polyclonal antibody CPP32 (caspase-3; Novocastra Laboratories Ltd, Newcastle upon Tyne, UK), which recognizes the proenzyme as well as the active form. As a negative control, the sections were incubated with the omission of DNTT and CASP3, and the equilibration buffer was substituted for the volume of the two reagents, as suggested by the manufacturer. As a positive control, normal female rodent mammary gland tissue sections were used (Intergen Company). The specificity of the double immunostaining was verified by localizing each antigen separately (data not shown). Finally, the tissue sections were counterstained with 4',6- 
diamidino-2-phenylindole (DAPI, Sigma) at 1:100 in PBS for 10 min (Martelli et al. 2006).

Tissue sections were analysed at a magnification of $400 \times$. The results were expressed as the percentage of apoptotic cells (TUNEL-positive and/or caspase-3-positive cells) on the total number of cells (DAPI-stained nuclei; Wulff et al. 2002, Berardinelli et al. 2004).

\section{Ki-67 and vWF}

Double immunostaining for $\mathrm{Ki}-67$ and vWF was performed according to Polak \& Van Noorden (1997). Tissue sections, after rehydration, were kept in $2 \%$ hydrogen peroxide (Merck) in methanol (Merck) for $5 \mathrm{~min}$ to remove endogenous peroxidase activity. The slides were placed in citrate buffer $(\mathrm{pH} 6)$, and antigen retrieval was performed by treating the sections twice in a hotbox oven $(\mathrm{HO})$ at $95^{\circ} \mathrm{C}$, washed with PBS for $5 \mathrm{~min}$ and then in TNT buffer (0.1 M Tris- $\mathrm{HCl}(\mathrm{pH} 7.5)$, containing $0.15 \mathrm{M} \mathrm{NaCl}$ and $0.05 \%$ Tween 20) for 5 min twice. After incubation in TNB blocking buffer $(0.1 \mathrm{M}$ Tris- $\mathrm{HCl}(\mathrm{pH}$ 7.5), $0.15 \mathrm{M} \mathrm{NaCl}$ and $0.5 \%$ of the blocking reagent supplied in the kit) for $1 \mathrm{~h}$ to prevent non-specific binding, the sections were incubated with a mouse monoclonal anti-Ki-67 primary antibody (Dako, Glostrup, Denmark) diluted 1:75 in TNT, and with a rabbit anti-vWF polyclonal primary antibody (Dako) diluted 1:400 in TNT, at RT overnight. VWF immunocomplexes were revealed by incubating the tissue sections with $\mathrm{CY} 3-$ labelled secondary goat anti-rabbit antibody (Chemicon, Billerica, MA, USA) diluted 1:100 in TNT. Ki-67 immunocomplexes were incubated with biotinylated-conjugated antimouse antibody (Sigma), and then detected by TSA Fluorescein System (Perkin-Elmer Life Sciences, Boston, MA, USA), according to the manufacturer's protocol. TNB blocking buffer was used in place of the primary antisera as a negative control. As a positive control, human breast carcinoma tissue samples (Heffelfinger et al. 2000, Martelli et al. 2006), kindly gifted by Dr De Carolis from the 'Giuseppe Mazzini' Hospital of Teramo, were used (Supplementary Fig. 1, which can be viewed online at www.reproduction-online.org/supplemental). The specificity of the double immunostaining was verified by localizing each antigen separately (data not shown). Tissue sections were counterstained with DAPI and analysed at a magnification of $400 \times$. The quantification of the digitized fluorescent signals was accomplished using a semi-automated algorithm written with the image analysis system KS300. A guided program (macro for KS300) was created to count 1) the number of proliferating granulosa or theca cells (green-stained cells), 2) the number of PEs (dual-stained cells for Ki-67 and vWF) and 3) the total number (blue-stained cells) of granulosa or theca cells, inside a fixed area of $10000 \mu \mathrm{m}^{2}$ of granulosa/theca compartment. In brief, after background densitometric calibration, the algorithm detected and separated the fluorescent regions of interest from their background and created a new image on the basis of their grey values. Thus, the process created a binary image from true colour image. The analyses were performed on the whole area of the cross section. The somatic (granulosa/ theca) PI was calculated as the percentage of Ki-67-positive granulosa or theca cells on the number of total somatic cells in the relative compartment. As a consequence, for each follicle, the PI was expressed either for theca or granulosa layers (Wulff et al. 2001, Watson \& Al Zi'abi 2002). Moreover, the proportion of PEs was calculated as the percentage of PEs (number of dual-stained cells for Ki-67 and vWF) on the total number of proliferating theca cells (PE/PT; Wulff et al. 2001, Bauer et al. 2003).

In order to eliminate from the quantitative analyses the background due to the red blood cell autofluorescence, the sections were restained with $\mathrm{HE}$ and micrographs of the same fluorescent fields were performed to identify and subtract the red blood cells within each blood vessel analysed.

\section{$v W F$}

In order to identify endothelial cells, after endogenous peroxidase inhibition and $\mathrm{HO}$ treatment performed as described previously, the slides were incubated first with normal goat serum (NGS; Sigma) for $30 \mathrm{~min}$ and then with a rabbit antibody against vWF (the same antibody used for the double immunostaining; Dako). For this analysis, the secondary antibody used was an anti-rabbit biotinylated-conjugated (1:100 in PBS/1\% BSA) applied for $1 \mathrm{~h}$ at RT. The samples were finally exposed to the avidin-biotin peroxidase complex (Vectastain ABC kit; Vector Laboratories, Burlingame, CA, USA) for $1 \mathrm{~h}$ at RT. The immunocomplex was then detected using 3,3'-diaminobenzidine (DAB; DBH Laboratory Supplies, Poole, UK) for $7 \mathrm{~min}$. To enhance the DAB reaction products, the ammonium nickel sulphate method was performed (Shu et al. 1988), which turns the brown DAB reaction into a black one. Sections were not counterstained so that quantitative image analysis could be performed (Wulff et al. 2001, Martelli et al. 2006). To quantify the VA (i.e. vWF immunopositivity), the tissue sections were measured at a magnification of $400 \times$. In brief, after geometric and densitometric calibration, the captured grey scale image was thresholded and converted into a binary image. The image analysis system generates one image where the terminal total area appears in black against a white background. Using a semi-automated algorithm, the computer program provides measurements of the area by counting the total number of pixels in the field. The VA was given by the extension of vWF-positive area in $\mu \mathrm{m}^{2} / 10000 \mu \mathrm{m}^{2}$. The analysis was performed on the whole area of the cross section (Barboni et al. 2004, Martelli et al. 2006).

\section{VEGFA}

The distribution of VEGFA within the follicular somatic compartments was visualized, after endogenous peroxidase inhibition and $\mathrm{HO}$ treatment, with a primary rabbit anti-human VEGFA (Calbiochem, Darmstadt, Germany) diluted 1:10 in $\mathrm{PBS} / 1 \% \mathrm{BSA}$, at RT overnight. After a secondary biotinylatedconjugated anti-rabbit antibody (1:100 in PBS/1\% BSA; Sigma), the immunocomplex was detected by the DAB reaction products as described above. Human breast carcinoma tissue samples (Heffelfinger et al. 2000, Martelli et al. 2006) were used as a positive control. NGS was used as a negative control in place of primary antibody (Supplementary Fig. 1).

Two or more sections per preantral follicle were qualitatively analysed to evaluate the intrafollicular presence and distribution of the angiogenic factor. 


\section{In situ hybridisation}

In situ hybridisation was performed with a commercially available kit (HybriProbe kit; Biognostik, Göttingen, Germany) according to Barboni et al. (2004) and Martelli et al. (2006). A custom synthesized oligonucleotide double-FITC-labelled cDNA probe for porcine VEGFA VE4 $_{16}$ was obtained from Biognostik. The design process of the oligonucleotide sequence was based on accession no. X81380 (porcine mRNA for VEGF). Probe sequence $\left(5^{\prime}-3^{\prime}\right)$ was as follows: $5^{\prime}$-CAC GTC TGC GGA TCT TGT ACA AAC AAA TGC-3' (Barboni et al. 2004, Martelli et al. 2006).

As negative control, sections were treated with a random double-FITC-labelled oligonucleotide probe containing the same proportion of cytosine and guanine bases as the VEGFA probe supplied by the manufacturer. According to the manufacturer's protocol, as a positive control, the probe for mRNA of housekeeping gene $\beta$-actin was used (Supplementary Fig. 1).

To identify the VEGFA mRNA expressing cells, the tissue sections were assessed at $400 \times$ magnification. After geometric and densitometric calibration, the image was captured in grey scale, thresholded and converted to a binary image. The results were expressed as the number of positive cells/unit area $\left(10000 \mu \mathrm{m}^{2}\right)$, calculated individually for theca and granulosa compartments (Barboni et al. 2004, Martelli et al. 2006) for each preantral follicle analysed.

\section{Biochemical investigations}

Oocytes collection

Preantral follicles were mechanically isolated, with the aid of a stereomicroscope, as described previously (Cecconi et al. 1999, Shuttleworth et al. 2002). After isolation, healthy follicles were selected on the basis of their morphology (Shuttleworth et al. 2002). Follicle diameters were measured with the aid of an inverted phase microscope equipped with an ocular micrometer $(40 \times$ magnification), and class 3-6 preantral follicles were collected. From each follicle, the cumulusoocyte complexes were recovered, and classified as healthy if they displayed a compact cumulus and an oocyte with a homogeneous ooplasm (Cecconi et al. 1999). Oocytes were mechanically separated from the surrounding cumulus cells, and zona pellucida, pooled (150 oocytes) and frozen until use for western blot or RT-PCR analyses. To exclude individual differences among animals, the follicles were collected from at least ten different pigs.

\section{Western blot analysis}

Total proteins were extracted from denuded oocytes according to Cecconi et al. (2008). Briefly, the cells were transferred into $30 \mu \mathrm{l}$ extraction buffer (Cecconi et al. 2008) and an aliquot was used to evaluate the amount of protein by Lowry's method (Lowry et al. 1951). The proteins extracted from the granulosa layer (Martelli et al. 2006) were used as positive control of the procedure.

Fifty micrograms of protein were separated by $12 \%$ SDSPAGE and then electrophoretically transferred to a nitrocellulose membrane (Hybond-C Extra; Amersham Pharmacia) for immunoblot analysis, according to standard protocols (Towbin et al. 1979). According to Martelli et al. (2006), the membranes were incubated with the polyclonal anti-human VEGFA-Ab2 (dilution 1:80; Oncogene, San Diego, CA, USA) that recognizes the swine VEGFA protein, and then with the peroxidase-conjugated anti-rabbit antibody (dilution 1:4000; Santa Cruz Biotechnology, Inc., Santa Cruz, CA, USA). After the stripping procedures (Martelli et al. 2006), the filter was reprobed with a monoclonal anti- $\alpha$-tubulin (dilution 1:5000; Sigma) and then with a peroxidase-conjugated antimouse antibody (dilution 1:4000; Santa Cruz Biotechnology, Inc). The signals were detected using the ECL western blot analysis system (Amersham Pharmacia).

Quantitative data were determined as the mean ratio of the optical density of the specific bands normalized to that of $\alpha$-tubulin. The densitometric analysis was carried out with the Advanced Image Data Analyzer (Rai Test, GmbH, Straubenhardt, Germany; Martelli et al. 2006). The experiments were repeated three times independently with similar results.

\section{Total RNA extraction and reverse transcription}

Total RNA from denuded oocytes or granulosa cells (as positive control) was extracted by TRIzol reagent (Invitrogen Life Technologies), according to the manufacturer's instructions. Purified RNA was resuspended in $15 \mu \mathrm{l}$ RNase-free water and was spectrophotometrically quantified (A260 nm). One microgram of RNA was electrophoretically separated in 1\% agarose gel in order to determine total RNA quality. Two micrograms of total RNA were reverse transcribed (RT) to cDNA using Omniscript Reverse Transcriptase kit (Qiagen SpA) in a final volume of $20 \mu \mathrm{l}$, according to the manufacturer's instruction. Transcription reactions without RT were performed as a control for DNA contamination.

\section{PCR analyses}

Based on swine gene sequences present in the GenBank, the primer for VEGFA 164 splice variant was designed using Primers Express Software (Applied Biosystems, Warrington, UK). The following primers were used:

- VEGFA 164 (accession no. X81380): 5'-GAAGTGGTGAAGTTCATGGA-3' (forward) and 5'-GCCTTGCAACGCGAGTCTGT-3' (reverse)

- $\beta$-Actin (accession no. U07786, (Shimizu et al. 2002)): 5'-ATCGTGCGGGACATCAAGGA-3' (forward) and 5'-AGGAGGGAGGGCTGGAAGAG-3' (reverse).

They amplify at 507 and 178 bp fragments size respectively. Semi-quantitative PCR was performed in the ThermoCycler (Biometra $\mathrm{GmbH}$, Goettingen) using ReadyMix Taq without $\mathrm{MgCl}_{2}$ (Sigma). A master mix for the following reaction components was prepared to the following final concentrations: $1.25 \mu \mathrm{l}$ forward primer $(0.25 \mu \mathrm{M}), 1.25 \mu \mathrm{l}$ reverse primer $(0.25 \mu \mathrm{M}), 12.5 \mathrm{PCR}$ master mix, $1.5 \mu \mathrm{MgCl}_{2}(1.5 \mu \mathrm{M})$, $5 \mu \mathrm{l}$ cDNA and $3.5 \mu \mathrm{l}$ RNase/DNase-free water to final volume of $25 \mu \mathrm{l}$. All samples were performed in duplicate for all genes. The PCR protocol employed was as follows: start denaturation 
for 5 min at $95^{\circ} \mathrm{C}, 40$ cycles at $95^{\circ} \mathrm{C}$ for $1 \min , 56{ }^{\circ} \mathrm{C}$ for $1 \mathrm{~min}$, $72{ }^{\circ} \mathrm{C}$ for $1 \mathrm{~min}$ and long extension for $4 \mathrm{~min}$ at $72{ }^{\circ} \mathrm{C}$. Each sample was run in duplicate, and the results were normalized to the level of housekeeping $\beta$-actin gene mRNA levels.

\section{Statistical analysis}

The data obtained from each preantral follicle were analysed within the different classes of follicles expressed as median and range (first and third quartiles). The values of somatic (granulosa/theca) PI, VA, VEGFA mRNA and ratio of PEs to PTs (PE/PT) variables obtained within the different classes of preantral follicles were then compared using the nonparametric Kruskal-Wallis test followed by the ConoverInman post hoc test. The correlation existing between each couple of variables was measured by a correlation test. The statistical difference was set at $P<0.05$ or $P<0.01$.

Finally, for each class of preantral follicle, a multivariate hierarchical cluster analysis was performed to build a dendrogram aggregating the data of somatic PI, VA, VEGFA mRNA and PE/PT obtained from each single follicle analysed to determine their similarity. In particular, this statistical technique performs the partitioning of a dataset (preantral follicles) into data subsets (clusters) defined on the basis of the considered parameters obtained from each single follicle and analysed altogether. Each subset shares a common trait (the proximity) according to a defined distance measure, which will determine how the similarity of elements is calculated. Hierarchical clustering builds a hierarchy of clusters represented by a tree (called a dendrogram), with individual elements at one end and a single cluster containing every element at the other. Since the dendrogram ordinates all the follicles into data subsets, a non-parametric statistical analysis (as described above) was performed to assess the significance of each partition. Where the difference was not significant $(P>0.05)$, the dendrogram was cut (cutting value).

For all calculations, the StatistiXL 1.7 beta program was used.

\section{Declaration of interest}

The authors declare that there is no conflict of interest that could be perceived as prejudicing the impartiality of the research reported.

\section{Funding}

This work was supported by a grant from MIUR-PRIN 2004.

\section{Acknowledgements}

The authors thank Terenzio Frabboni, Zeiss advisor, for his technical assistance with KS300 computer image analysis system.

\section{References}

Abramovich D, Parborell F \& Tesone M 2006 Effect of a vascular endothelial growth factor (VEGF) inhibitory treatment on the folliculogenesis and ovarian apoptosis in gonadotropin-treated prepubertal rats. Biology of Reproduction 75 434-441.

Barboni B, Turriani M, Galeati G, Spinaci M, Bacci ML, Forni M \& Mattioli M 2000 Vascular endothelial growth factor production in growing pig antral follicles. Biology of Reproduction 63 858-864.

Barboni B, Martelli A, Berardinelli P, Russo V, Turriani M, Bernabo N, Lucidi P \& Mattioli M 2004 Ovarian follicle vascularization in fasted pig. Theriogenology 62 943-957.

Bauer M, Schilling N \& Spanel-Borowski K 2003 Development and regression of non-capillary vessels in the bovine corpus luteum. Cell and Tissue Research 311 199-205.

Berardinelli P, Martelli A, Russo V, Nardinocchi D, Turriani M, Barboni B, Mattioli M, Scapolo PA \& Clavenzani P 2002 Correlation between VEGF production and blood vessels density in steroidogenic activated pig antral follicles. Italian Journal of Anatomy and Embryology $\mathbf{1 0 7}$ 115-126.

Berardinelli P, Russo V, Martelli A, Nardinocchi D, Di Giacinto O, Barboni B \& Mattioli M 2004 Colocalization of DNA fragmentation and caspase-3 activation during atresia in pig antral follicles. Anatomia, Histologia, Embryologia 33 23-27.

Carmeliet P, Ferreira V, Breier G, Pollefeyt S, Kieckens L, Gertsenstein M, Fahrig M, Vandenhoeck A, Harpal K, Eberhardt C et al. 1996 Abnormal blood vessel development and lethality in embryos lacking a single VEGF allele. Nature 380 435-439.

Cecconi S, Barboni B, Coccia M \& Mattioli M 1999 In vitro development of sheep preantral follicles. Biology of Reproduction 60 594-601.

Cecconi S, Mauro A, Capacchietti G, Berardinelli P, Bernabo N, Di Vincenzo AR, Mattioli M \& Barboni B 2008 Meiotic maturation of incompetent prepubertal sheep oocytes is induced by paracrine factor(s) released by gonadotropin-stimulated oocyte-cumulus cell complexes and involves mitogen-activated protein kinase activation. Endocrinology 149 100-107.

Danforth DR 1995 Endocrine and paracrine control of oocyte development. American Journal of Obstetrics and Gynecology 172 747-752.

Danforth DR, Arbogast LK, Ghosh S, Dickerman A, Rofagha R \& Friedman CI 2003 Vascular endothelial growth factor stimulates preantral follicle growth in the rat ovary. Biology of Reproduction 68 1736-1741.

Diaz FJ, Wigglesworth K \& Eppig JJ 2007 Oocytes determine cumulus cell lineage in mouse ovarian follicles. Journal of Cell Science $\mathbf{1 2 0}$ 1330-1340.

Drummond AE 2006 The role of steroids in follicular growth. Reproductive Biology and Endocrinology 416.

Erickson GF \& Danforth DR 1995 Ovarian control of follicle development. American Journal of Obstetrics and Gynecology 172 736-747.

Ferrara N 1996 Vascular endothelial growth factor. European Journal of Cancer 32A 2413-2422.

Ferrara N \& Davis-Smyth T 1997 The biology of vascular endothelial growth factor. Endocrine Reviews 18 4-25.

Fortune JE 2003 The early stages of follicular development: activation of primordial follicles and growth of preantral follicles. Animal Reproduction Science 78 135-163.

Fraser HM 2006 Regulation of the ovarian follicular vasculature. Reproductive Biology and Endocrinology 418.

Gelety TJ \& Magoffin DA 1997 Ontogeny of steroidogenic enzyme gene expression in ovarian theca-interstitial cells in the rat: regulation by a paracrine theca-differentiating factor prior to achieving luteinizing hormone responsiveness. Biology of Reproduction 56 938-945.

Gougeon A 2004 Dynamics of human follicular growth: morphologic, dynamic and functional aspects. In The Ovary, 2 edn, pp 25-43. Eds PCK Leung \& EY Adashi. London: Elsevier, Academic press.

Griffin J, Emery BR, Huang I, Peterson CM \& Carrell DT 2006 Comparative analysis of follicle morphology and oocyte diameter in four mammalian species (mouse, hamster, pig, and human). Journal of Experimental \& Clinical Assisted Reproduction 32. 
Hazzard TM, Molskness TA, Chaffin CL \& Stouffer RL 1999 Vascular endothelial growth factor (VEGF) and angiopoietin regulation by gonadotrophin and steroids in macaque granulosa cells during the peri-ovulatory interval. Molecular Human Reproduction 5 1115-1121.

Heffelfinger SC, Yassin R, Miller MA \& Lower EE 2000 Cyclin D1, retinoblastoma, p53, and Her2/neu protein expression in preinvasive breast pathologies: correlation with vascularity. Pathobiology 68 129-136.

Hull ML, Charnock-Jones DS, Chan CL, Bruner-Tran KL, Osteen KG, Tom BD, Fan TP \& Smith SK 2003 Antiangiogenic agents are effective inhibitors of endometriosis. Journal of Clinical Endocrinology and Metabolism 88 2889-2899.

Hunter MG, Hudson N, Mitchell M, Walker RM \& Webb R 2004 Resumption of follicle growth in gilts after ovarian autografting. Animal Reproduction Science 80 317-328.

Hutt KJ \& Albertini DF 2007 An oocentric view of folliculogenesis and embryogenesis. Reproductive Biomedicine Online 14 758-764.

Isobe N, Kitabayashi M \& Yoshimura Y 2005 Microvascular distribution and vascular endothelial growth factor expression in bovine cystic follicles. Domestic Animal Endocrinology 29 634-645.

Kaczmarek MM, Schams D \& Ziecik AJ 2005 Role of vascular endothelial growth factor in ovarian physiology - an overview. Reproductive Biology 5 111-136.

Knight PG \& Glister C 2006 TGF-beta superfamily members and ovarian follicle development. Reproduction 132 191-206.

Knox RV 2005 Recruitment and selection of ovarian follicles for determination of ovulation rate in the pig. Domestic Animal Endocrinology 29 385-397.

Kotsuji F \& Tominaga T 1994 The role of granulosa and theca cell interactions in ovarian structure and function. Microscopy Research and Technique 27 97-107.

Lammert E, Cleaver O \& Melton D 2001 Induction of pancreatic differentiation by signals from blood vessels. Science 294 564-567.

Lowry OH, Rosenbrough NJ, Farr AL \& Randall RJ 1951 Protein measurement with the Folin phenol reagent. Journal of Biological Chemistry 193 265-275.

Lundy T, Smith P, O'Connell A, Hudson NL \& McNatty KP 1999 Populations of granulosa cells in small follicles of the sheep ovary. Journal of Reproduction and Fertility 115 251-262.

Martelli A, Berardinelli P, Russo V, Mauro A, Bernabo N, Gioia L, Mattioli M \& Barboni B 2006 Spatio-temporal analysis of vascular endothelial growth factor expression and blood vessel remodelling in pig ovarian follicles during the periovulatory period. Journal of Molecular Endocrinology 36 107-119.

Mattioli M, Barboni B, Turriani M, Galeati G, Zannoni A, Castellani G, Berardinelli P \& Scapolo PA 2001 Follicle activation involves vascular endothelial growth factor production and increased blood vessel extension. Biology of Reproduction 65 1014-1019.

McGee EA \& Hsueh AJ 2000 Initial and cyclic recruitment of ovarian follicles. Endocrine Reviews 21 200-214.

McGee EA, Perlas E, LaPolt PS, Tsafriri A \& Hsueh AJ 1997 Folliclestimulating hormone enhances the development of preantral follicles in juvenile rats. Biology of Reproduction 57 990-998.

Moor RM \& Seamark RF 1986 Cell signaling, permeability, and microvasculatory changes during antral follicle development in mammals. Journal of Dairy Science 69 927-943.

Morbeck DE, Esbenshade KL, Flowers WL \& Britt JH 1992 Kinetics of follicle growth in the prepubertal gilt. Biology of Reproduction 47 485-491.

Neufeld G, Cohen T, Gengrinovitch S \& Poltorak Z 1999 Vascular endothelial growth factor (VEGF) and its receptors. FASEB Journal 13 9-22.

Otani N, Minami S, Yamoto M, Shikone T, Otani H, Nishiyama R, Otani T \& Nakano R 1999 The vascular endothelial growth factor/fms-like tyrosine kinase system in human ovary during the menstrual cycle and early pregnancy. Journal of Clinical Endocrinology and Metabolism $\mathbf{8 4}$ 3845-3851.
Polak MJ \& Van Noorden S 1997 Multiple immunostaining. In Microscopy Handbooks n.37 Introduction to Immunocytochemistry, pp 73-80. Oxford: Bios Scientific Publisher.

Redmer DA \& Reynolds LP 1996 Angiogenesis in the ovary. Reviews of Reproduction 1 182-192.

Roberts AE, Arbogast LK, Friedman CI, Cohn DE, Kaumaya PT \& Danforth DR 2007 Neutralization of endogenous vascular endothelial growth factor depletes primordial follicles in the mouse ovary. Biology of Reproduction 76 218-223.

Shimizu T 2006 Promotion of ovarian follicular development by injecting vascular endothelial growth factor (VEGF) and growth differentiation factor 9 (GDF-9) genes. Journal of Reproduction and Development 52 23-32.

Shimizu T \& Sato E 2005 Manipulation of ovarian follicle development by injecting vascular endothelial growth factor (VEGF) gene. Reproductive Biology 5 257-268.

Shimizu T, Jiang JY, Sasada H \& Sato E 2002 Changes of messenger RNA expression of angiogenic factors and related receptors during follicular development in gilts. Biology of Reproduction 67 1846-1852.

Shu SY, Ju G \& Fan LZ 1988 The glucose oxidase-DAB-nickel method in peroxidase histochemistry of the nervous system. Neuroscience Letters 85 169-171.

Shuttleworth G, Broughton PF \& Hunter MG 2002 In vitro development of pig preantral follicles cultured in a serum-free medium and the effect of angiotensin II. Reproduction 123 807-818.

Sicinski P, Donaher JL, Geng Y, Parker SB, Gardner H, Park MY, Robker RL, Richards JS, McGinnis LK, Biggers JD et al. 1996 Cyclin D2 is an FSHresponsive gene involved in gonadal cell proliferation and oncogenesis. Nature 384 470-474.

Stouffer RL, Martinez-Chequer JC, Molskness TA, Xu F \& Hazzard TM 2001 Regulation and action of angiogenic factors in the primate ovary. Archives of Medical Research 32 567-575.

Towbin H, Staehelin T \& Gordon J 1979 Electrophoretic transfer of proteins from polyacrylamide gels to nitrocellulose sheets: procedure and some applications. PNAS 76 4350-4354.

Watson ED \& Al Zi'abi MO 2002 Characterization of morphology and angiogenesis in follicles of mares during spring transition and the breeding season. Reproduction 124 227-234.

Wulff C, Wiegand SJ, Saunders PT, Scobie GA \& Fraser HM 2001 Angiogenesis during follicular development in the primate and its inhibition by treatment with truncated Flt-1-FC (vascular endothelial growth factor Trap(A40)). Endocrinology 142 3244-3254.

Wulff C, Wilson H, Wiegand SJ, Rudge JS \& Fraser HM 2002 Prevention of thecal angiogenesis, antral follicular growth, and ovulation in the primate by treatment with vascular endothelial growth factor Trap R1R2. Endocrinology 143 2797-2807.

Yang MY \& Fortune JE 2006 Testosterone stimulates the primary to secondary follicle transition in bovine follicles in vitro. Biology of Reproduction 75 924-932.

Yang MY \& Fortune JE 2007 Vascular endothelial growth factor stimulates the primary to secondary follicle transition in bovine follicles in vitro. Molecular Reproduction and Development 74 1095-1104.

Zimmermann RC, Hartman T, Kavic S, Pauli SA, Bohlen P, Sauer MV \& Kitajewski J 2003 Vascular endothelial growth factor receptor 2-mediated angiogenesis is essential for gonadotropin-dependent follicle development. Journal of Clinical Investigation 112 659-669.

Received 14 March 2008

First decision 28 May 2008

Revised manuscript received 2 September 2008

Accepted 7 October 2008 